\title{
Class Ratio Transform with an Application to Describing the Roughness Anisotropy of Natural Rock Joints
}

\author{
Rui Yong, ${ }^{1,2}$ Lei Huang, ${ }^{3}$ Qinkuan Hou $\mathbb{D}^{1}{ }^{1}$ and Shigui Du ${ }^{1,2}$ \\ ${ }^{1}$ Zhejiang Collaborative Innovation Centre for Prevention and Control of Mountain Geological Hazards, Shaoxing University, \\ Shaoxing, Zhejiang 312000, China \\ ${ }^{2}$ School of Civil and Environmental Engineering, Ningbo University, Ningbo, Zhejiang 315211, China \\ ${ }^{3}$ Three Gorges Research Center for Geohazards, Ministry of Education, China University of Geosciences, Wuhan, \\ Hubei 430074, China
}

Correspondence should be addressed to Qinkuan Hou; houqinkuan@hotmail.com

Received 10 October 2019; Revised 20 July 2020; Accepted 23 August 2020; Published 3 September 2020

Academic Editor: Wensu Chen

Copyright (c) 2020 Rui Yong et al. This is an open access article distributed under the Creative Commons Attribution License, which permits unrestricted use, distribution, and reproduction in any medium, provided the original work is properly cited.

In this study, we explore the potential of class ratio transform with an application to describing the roughness anisotropy of natural rock joints. Roughness smooth coefficient, used for suitably smoothing the roughness parameter values to realize an anisotropic model, is proposed to represent the apparent anisotropy of surface roughness. The geometric irregularities of roughness parameters in polar plots allow transforming to a regular roughness asperity pattern, which can be readily approximated by the ellipse function. The joint roughness coefficients in different orientations of natural rock joints were measured and revealed to be identical after applying the smoothing process using the class ratio transform method. The results show that the roughness smooth coefficient increases with sample size but decreases as azimuthal interval narrows. This method demonstrates the ability in describing the roughness anisotropy and inferring the roughness parameters $Z_{2}, R_{p}$, and $\theta_{\max }^{*} /(C+1)_{2 D}$.

\section{Introduction}

Rock joints have significant influences on the mechanical properties and deformation behavior of rock masses [1-6]. Surface roughness, among the most important rock joint attributes, is fundamental for estimating true contact areas and modelling the hydromechanical response of joint asperities during contact between wall surfaces [7-9]. Barton and Quadros [10] stated that anisotropy is everywhere in rock engineering and anisotropic behavior is widespread because of the combined effects of anisotropic structure. Rock joints are formed through diverse, complex fracture mechanisms; this, coupled with the general complexities of rock masses, results in significant anisotropy of rock joint surfaces. The variation of the joint roughness in different directions has been recognized as an important source of anisotropic behaviors of rock joints. The roughness anisotropy of rock joints provides pertinent information for both engineering and geological perspectives [11].
To quantify the surface anisotropy, Belem et al. [12] quantified the primary roughness of rock joint surface by the degree of apparent anisotropy which is defined by the means of linear parameter calculated along $x$ - or $y$-axis. Bae et al. [13] estimated the directional anisotropy of the joint roughness based on the half scan circle technique. Yang et al. [14] described the anisotropy of the joint surface by a $2 \mathrm{D}$ directional Hurst index expressed in a Fourier series form. Kulatilake et al. [15] investigated the roughness anisotropy of natural rock joints through the variogram technique and studied the effect of scale on anisotropy and variability of natural rock joint roughness. Baker et al. [16] developed an automatic technique to detect anisotropic features on rock faces by fractal analysis and plotting roughness along different orientations. Mah et al. [11] characterized the joint surface anisotropy based on the joint roughness coefficient values in different orientations. The results illustrated that the surface roughness of natural rock joints was anisotropic and the roughness varies in a random manner in polar plots. 
Although the characteristic of roughness anisotropy can be found by the irregular patterns in the polar plots, the anisotropic roughness failed to be described with a quantified value. Moreover, the roughness parameters are significantly influenced by the sample sizes $[17,18]$, and the scale effect on surface roughness has been proven to be an inherent property of rock joints [19]. The study of the scale effect on the directional joint roughness is strongly required in studying the roughness anisotropic characteristics.

Over the last three decades, many researchers have investigated the surface roughness of rock joints using threedimensional (3D) roughness evaluation methods [19-22]. However, the characteristics of rock roughness anisotropy are not fully reflected by these $3 \mathrm{D}$ roughness parameters, because, besides the surface anisotropy, 3D rock joint roughness is influenced by many factors including asperity inclination, asperity amplitude, and sample size. The roughness estimation approaches based on two-dimensional (2D) roughness parameters (e.g., joint roughness coefficient JRC, the first derivative root-mean-square $Z_{2}$, and the roughness profile index or profile sinuosity $R_{p}$ ) have been considered as the widely accepted approach in rock engineering for many years. Therefore, the roughness anisotropy of natural rock joint planes is often revealed by joint roughness values of the $2 \mathrm{D}$ profile extracted from the joint surface at certain azimuthal increments from $0^{\circ}$ to $360^{\circ}$ [23-25]. The directional roughness values are always plotted for presenting any directional roughness variability of the rock joint surfaces. If a regular roughness anisotropic pattern exists, then the polar plot of roughness parameters is expected to show elliptical symmetry [21]. Therefore, the polar plot of directional roughness is generally assumed to follow an elliptical distribution for simplifying the anisotropy matter. Jing et al. [26] assumed that the magnitude of the asperity angle follows an elliptical distribution. Belem et al. [12] characterized the anisotropy of rock joint surface using the null iso-correlation and described the anisotropy based on the mathematical definition of an ellipse in XOY coordinates system. However, the roughness of rock joint surfaces varies randomly with the variation of orientation. Unfortunately, there is no guarantee that a definite elliptical pattern exists for illustrating the polar plots of the roughness parameters. Furthermore, previous studies do not provide full indications for how to determine the azimuthal increment of the roughness measurement directions, and the influence of azimuthal increment on surface anisotropy evaluation remains largely unsolved.

To solve these problems and to quantitatively estimate the anisotropic roughness properties of joint surfaces, in this study, we (1) present a data (roughness parameters) transforming method for approximating the asperity ellipse; (2) define the roughness smooth coefficient for describing the apparent anisotropy of roughness surface; and (3) analyze the factors affecting the roughness smooth coefficient.

\section{Class Ratio Transform}

Class ratio transform is a statistical method of processing data. Data transform is achieved by taking the ratio of each data in the original sequence to the next data as new data of the sequence. This transform can effectively weaken the randomness, fuzziness, and uncertainty of the original data and make the chaotic original data present more obvious characteristics. In many engineering problems, due to a variety of uncertain factors, the data characteristics we obtained are usually irregular, and the class ratio transform is a powerful way to optimize the data $[27,28]$.

In grey theory, the class ratio is usually used to deal with the smoothness of a data sequence and improve the approximation accuracy of an exponential model. Hence, it plays an important role in deciding the accuracy of a prediction model [29-31]. Assume that there is a data sequence:

$$
x_{0}=\left(x_{0}(1), x_{0}(2), \ldots, x_{0}(n)\right)
$$

The class ratio sequence is defined as

$$
y_{0}(k)=\frac{x_{0}(k-1)}{x_{0}(k)},
$$

where $k=2,3, \ldots, n$, and the class ratio should satisfy the approximating condition $y_{0}(k) \in\left[e^{-(2 /(n+1))}, e^{2 /(n+1)}\right]$ to reach better approximation performance. For instance, if $n=12$, then $y_{0}(k)$ lies in the range of $[0.8574,1.1663]$. To realize the class ratio sequence in a required range, one can deal with the original data sequence by the following transforms:

(1) Translational transform: $x_{1}(k)=x_{0}(k)+q$ ( $q$ is a constant)

(2) Root transform: $\mathrm{x}_{1}(k)=\sqrt[m]{x_{0}(k)}(m \geq 2)$

(3) Logarithmic transform: $\mathrm{x}_{1}(k)=\ln \left(\mathrm{x}_{0}(k)\right)$

One of the three transformation techniques can be used to recurrently process the original data sequence until the class ratio condition is satisfied.

The roughness parameter values can be processed smoothly by the process of the class ratio. Thus, the plot shape indicated by the directional variability of roughness parameter values of the rock joints tends to have an ellipse shape with a systematic directional variation, which can be expressed by an ellipse function (so-called anisotropy ellipse).

Let us consider the following roughness parameter sequence:

$$
r_{0}=\left(r_{0}(1), r_{0}(2), \ldots, r_{0}(t)\right)
$$

where $t$ equals $360 / \lambda+1$ and $\lambda$ is the azimuthal interval.

Then, the roughness parameter values sequence is processed by some transform as follows:

$$
R_{0}=\left(R_{0}(1), R_{0}(2), \ldots, R_{0}(t)\right)
$$

Here, we used the exponential transform $R_{1}(i)=r_{0}(i)^{(1 / m)}$ for $i=1,2, \ldots, t$, where $m$ ranges from 1 to $m_{0}$, and $m_{0}$ is defined as the roughness smooth coefficient. If the class ratio sequence $J=\left[R_{0}(1) / R_{0}(2), R_{0}(2) / R_{0}(3), \ldots\right.$, $\left.R_{0}(t-1) / R_{0}(t)\right]$ satisfies the condition $J \in\left[e^{-2 /(t+1)}, e^{2 /(t+1)}\right]$, then the smooth coefficient $m_{0}$ is taken for $m$. 
Let us consider a series of JRC values at an angular increment of $15^{\circ}$, as shown in Table 1. The JRC sequence $r_{0}$ $\left(=R_{0}\right)$ was processed by the exponential transform method as mentioned above. Here, $m$ takes the values of 3 and 5 as an example. The comparison of the polar plots in Figures 1(a)1 (c) reveals that (1) the shape of the polar plots of the original JRC values $(m=1)$ is quite irregular and difficult to be described by the elliptical function; (2) the shape of the processed JRC values $(m=3)$ is more regular than the original data, which tend to follow an elliptical distribution; (3) and the processed JRC values in the polar plots $(m=5)$ have a quite clear elliptical shape, in which the data difference between adjacent angles is obviously reduced. The class ratio sequence of $J_{1}, J_{3}, J_{5}$ is tabulated in Table 1 . The maximum and minimum class ratios of original JRC values (take $m=1$ ) are 1.335 and 0.573 , respectively. It denotes that the data difference between adjacent angles is distinct. When $m=3$ and $m=5$, the maximum class ratio is decreased to 1.101 and 1.060 , respectively, but the minimum class ratio is increased to 0.831 and 0.895 , respectively. Then, the class ratio sequence satisfies the required condition $J \in\left[e^{-2 /(t+1)}, e^{2 /(t+1)}\right]=[0.926,1.080]$ when $m$ is over 7.3. Therefore, the smooth coefficient $m_{0}$ in this example is determined to be 7.3.

As observed in Figure 2, the processed data shows an elliptical symmetry. For a convenient depiction of the elliptical function, processed data based on polar coordinate system is suggested to be transformed into Cartesian coordinates. The anisotropic ellipse function can be defined as

$$
A x^{2}+B x y+C y^{2}+D x+E y+F=0,
$$

where $x=R_{0} \cos \theta$ and $y=R_{0} \sin \theta$; $\theta$ is the estimated directional angle; and $A, B, C, D, E$, and $F$ are the polynomial coefficients. The characteristic coefficients of an ellipse function contain the major principal axis $a$, semi-minor axis $b$, center coordinates $\left(x_{\mathrm{c}}, y_{\mathrm{c}}\right)$, and rotation angle $\Theta$. The rotation angle $\Theta$ denotes the direction of major anisotropy, which means the joint roughness reaches the maximum value in this direction. These coefficients can be obtained by using the following formulae:

$$
\left\{\begin{array}{l}
a^{2}(\sin \Theta)^{2}+b^{2}(\cos \Theta)^{2}-A=0, \\
2\left(b^{2}-a^{2}\right) \sin \Theta \cos \Theta-B=0, \\
a^{2}(\cos \Theta)^{2}+b^{2}(\sin \Theta)^{2}-C=0 \\
2 A x_{c}+B y_{c}+D=0 \\
B x_{c}+2 C y_{c}+E=0
\end{array}\right.
$$

In this example, the values of the major principal axis $a$ and semi-minor axis $b$ are 1.454 and 1.391, respectively. Tatone [32] quantified the roughness anisotropy as the ratio of the maximum directional roughness to the minimum directional roughness according to the polar plots of the roughness parameters. Here, the parameter $\alpha=a / b$, i.e, the ratio of the major principal axis to the minor principal axis, is utilized to denote the anisotropic degree. In anisotropic ellipse, the major principal axis $a$ denotes the major anisotropy and its rotation angle $\Theta$ denotes the direction of major anisotropy. In this example, the anisotropic degree is $\alpha=1.045$, the orientation of major anisotropy $\Theta$ is $63.88^{\circ}$ (or $\left.243.88^{\circ}\right)$, and the orientation of minor anisotropy is $153.88^{\circ}$ (or $333.88^{\circ}$ ).

\section{Evaluation of Joint Roughness Anisotropy}

Several test samples were collected from the large exposed joint surfaces of the rock masses at Xiaolangdi Reservoir, Henan Province, China. The lithology of rock masses here is calcareous siltstone. The roughness samples were obtained from a persistent sub-vertical joint set of N70E, 83NW. The roughness surface contains several large exposures of natural, planar to undulating joint surfaces, and the roughness variations of the joint surface in different orientations are obviously susceptible to close observation and direct fragmentation touching. A series of roughness profiles were extracted from the joint surfaces at an angular increment of $15^{\circ}$. These profiles were recorded by the mechanical hand profilograph $[33,34]$ with the lengths of $100 \mathrm{~mm}, 200 \mathrm{~mm}$, $500 \mathrm{~mm}$, and $1000 \mathrm{~mm}$. The digitized profiles were obtained at a spacing of $0.5 \mathrm{~mm}$ by the grayscale image processing method.

The JRC values of test samples were scaled by Barton's graphical solution on the basis of the roughness amplitude/ joint length relationship with JRC as shown in Figure 3. Notably, a straight line is generated between the two local maxima of the digitized profile to simulate a straight edge apposed on the original rock joint surface. The normal distance from the straight line to each point along the surface profile is calculated to determine the maximum asperity amplitude. The JRC values are determined by Barton's empirical graphs according to the profile length and the maximum asperity amplitude. The JRC values are equal in opposing directions (i.e., $0^{\circ}$ and $180^{\circ}$ ). The JRC values of the test samples in different sizes are averaged and summarized in Table 2.

In Figure 4, the polar plots display the anisotropic patterns of different sized rock joint samples, and then the average JRC values in each orientation clearly illustrate a negative scale effect, in which the roughness values decrease with the profile length. The irregular shape of the data series indicates that there is a large variation in the JRC values for roughness profiles extracted from the same surface. The surface roughness of the test samples of length $100 \mathrm{~mm}$ shows a major anisotropy oriented at $0^{\circ}$ and a minor anisotropy at $90^{\circ}$. The joint profile set of $200 \mathrm{~mm}$ has a relatively low JRC with a major anisotropic orientation at almost $0^{\circ}$ and a minor one in the vicinity of $75^{\circ}$. The major and minor anisotropy orientations of the joint profile set of $500 \mathrm{~mm}$ are similar to those of $200 \mathrm{~mm}$ length samples and its JRC values are decreasing in all orientations. The surface roughness shows a minor anisotropy within the orientation range from $75^{\circ}$ to $135^{\circ}$. The surface roughness of the $1000 \mathrm{~mm}$ long test samples illustrates great roughness in the orientation of $0^{\circ}$ and small roughness in the orientation of $60^{\circ}$.

In Figures 5(a)-8(a), the plots of the JRC values obtained in different orientations are indicated to be relatively discrete. The ellipse curves fail to describe the anisotropic 
TABLE 1: Summary of the processed JRC data and class ratios.

\begin{tabular}{|c|c|c|c|c|c|c|c|c|}
\hline Orientation $\left({ }^{\circ}\right)$ & \multicolumn{2}{|c|}{$m=1$} & \multicolumn{2}{|c|}{$m=3$} & \multicolumn{2}{|c|}{$m=5$} & \multicolumn{2}{|c|}{$m_{0}=7.3$} \\
\hline 0 & 9.818 & 0.787 & 2.141 & 0.923 & 1.579 & 0.953 & 1.367 & 0.968 \\
\hline 15 & 12.471 & 1.067 & 2.319 & 1.022 & 1.656 & 1.013 & 1.413 & 1.009 \\
\hline 30 & 11.688 & 0.573 & 2.269 & 0.831 & 1.635 & 0.895 & 1.400 & 0.927 \\
\hline 45 & 20.395 & 1.081 & 2.732 & 1.026 & 1.828 & 1.016 & 1.511 & 1.011 \\
\hline 60 & 18.865 & 1.157 & 2.662 & 1.050 & 1.799 & 1.030 & 1.495 & 1.020 \\
\hline 75 & 16.306 & 1.335 & 2.536 & 1.101 & 1.748 & 1.060 & 1.466 & 1.040 \\
\hline 90 & 12.212 & 1.048 & 2.303 & 1.016 & 1.650 & 1.009 & 1.409 & 1.006 \\
\hline 105 & 11.652 & 0.829 & 2.267 & 0.940 & 1.634 & 0.963 & 1.400 & 0.975 \\
\hline 120 & 14.051 & 1.283 & 2.413 & 1.086 & 1.696 & 1.051 & 1.436 & 1.035 \\
\hline 135 & 10.955 & 0.990 & 2.221 & 0.997 & 1.614 & 0.998 & 1.388 & 0.999 \\
\hline 150 & 11.071 & 1.031 & 2.229 & 1.010 & 1.617 & 1.006 & 1.390 & 1.004 \\
\hline 165 & 10.737 & 1.094 & 2.206 & 1.030 & 1.608 & 1.018 & 1.384 & 1.012 \\
\hline 180 & 9.818 & 0.787 & 2.141 & 0.923 & 1.579 & 0.953 & 1.367 & 0.968 \\
\hline 195 & 12.471 & 1.067 & 2.319 & 1.022 & 1.656 & 1.013 & 1.413 & 1.009 \\
\hline 210 & 11.688 & 0.573 & 2.269 & 0.831 & 1.635 & 0.895 & 1.400 & 0.927 \\
\hline 225 & 20.395 & 1.081 & 2.732 & 1.026 & 1.828 & 1.016 & 1.511 & 1.011 \\
\hline 240 & 18.865 & 1.157 & 2.662 & 1.050 & 1.799 & 1.030 & 1.495 & 1.020 \\
\hline 255 & 16.306 & 1.335 & 2.536 & 1.101 & 1.748 & 1.060 & 1.466 & 1.040 \\
\hline 270 & 12.212 & 1.048 & 2.303 & 1.016 & 1.650 & 1.009 & 1.409 & 1.006 \\
\hline 285 & 11.652 & 0.829 & 2.267 & 0.940 & 1.634 & 0.963 & 1.400 & 0.975 \\
\hline 300 & 14.051 & 1.283 & 2.413 & 1.086 & 1.696 & 1.051 & 1.436 & 1.035 \\
\hline 315 & 10.955 & 0.990 & 2.221 & 0.997 & 1.614 & 0.998 & 1.388 & 0.999 \\
\hline 330 & 11.071 & 1.031 & 2.229 & 1.010 & 1.617 & 1.006 & 1.390 & 1.004 \\
\hline 345 & 10.737 & 1.094 & 2.206 & 1.030 & 1.608 & 1.018 & 1.384 & 1.012 \\
\hline 360 & 9.818 & $\begin{array}{l}J_{\max }=1.335 \\
J_{\min }=0.573\end{array}$ & 2.141 & $\begin{array}{l}J_{\max }=1.101 \\
J_{\min }=0.831\end{array}$ & 1.579 & $\begin{array}{l}J_{\max }=1.060 \\
J_{\min }=0.895\end{array}$ & 1.367 & $\begin{array}{l}J_{\max }=1.040 \\
J_{\min }=0.927\end{array}$ \\
\hline
\end{tabular}

${ }^{*} \mathrm{JRC}$ values $=R_{0}(m=1)$.

patterns with high-fitting precision. The difference between the JRC values can be diminished by processing the class ratio using the smooth coefficient $\mathrm{m} 0$. The processed JRC values are shown in Figures 5(b)-8(b). As shown in these figures, the anisotropic patterns are closely correlated to standard ellipse curves. Results indicate that the roughness smooth coefficient $m_{0}$ of the test samples in the length of $100 \mathrm{~mm}, 200 \mathrm{~mm}, 500 \mathrm{~mm}$, and $1000 \mathrm{~mm}$ is $3.3,3.6,3.9$, and 4.3. Interestingly, the roughness smooth coefficient grows with the sample size. Thus, it is appropriate to consider that the roughness anisotropy of large-sized rock joints is more evident than that of small ones.

Tatone [32] quantified the roughness anisotropy by the ratio of the maximum roughness to the minimum of the roughness parameters. The JRC roughness anisotropy ratios of the $100 \mathrm{~mm}, 200 \mathrm{~mm}, 500 \mathrm{~mm}$, and $1000 \mathrm{~mm}$ long test samples are $1.79,1.82,1.76$, and 1.79 , respectively. Their anisotropy degrees $\alpha$ are 1.12, 1.12, 1.14, and 1.13, respectively. These roughness anisotropy ratios or degrees seem to be random and unpredictable with the change in sample size. Hence, it is not adequate to indicate or capture the features of roughness anisotropy only through maximum or minimum values. As shown in Figures 5-8, the major anisotropy orientations $\Theta$ of most test samples $(100 \mathrm{~mm}, 500 \mathrm{~mm}$, and $1000 \mathrm{~mm}$ ) are approximately $0^{\circ}$. However, there is an exception of $200 \mathrm{~mm}$ long test samples that a tiny rotation occurs and its major anisotropy orientation $\Theta$ is $170.81^{\circ}$. These major anisotropy orientations agree with the visual observation of the surface-roughness parameter.
The class ratio condition $J \in\left[e^{-2 / t+1}, e^{2 / t+1}\right]$ is influenced by the azimuthal interval of measurement directions. Figure 9 shows the polar plots of JRC values in azimuthal interval of $30^{\circ}$ and $60^{\circ}$, respectively. In Figures 4 and 9, the polar plots of JRC values in smaller azimuthal interval indicate stronger anisotropy in different orientations. Therefore, the 2D roughness measurement with more details is significantly important for fully understanding the roughness anisotropy. Meanwhile, the roughness anisotropy evaluations and comparisons should be analyzed within the same azimuthal interval. The result in Figure 10 indicates that the roughness smooth coefficients get smaller values with the azimuthal interval decreasing. The difference caused by various azimuthal intervals is magnified in large-sized rock joints.

\section{Discussion on Other Related Roughness Parameters}

In order to quantitatively describe the roughness anisotropy of natural rock joints, the class ratio transform method can also be used to deal with other roughness parameters of interest along with JRC data. Researchers [36-39] have presented several roughness parameters for describing the geometric irregularities (waves) of rock joints. Among those parameters, the best results were achieved with $Z_{2}$ (equation (7)), first-derivative root-mean-square [37], $R_{p}$ (equation (8)), roughness profile index or profile sinuosity $[38,40]$, and the roughness metric $\theta_{\max }^{*} /(C+1)_{2 D}$ (equation (9)) proposed by [18], as follows: 


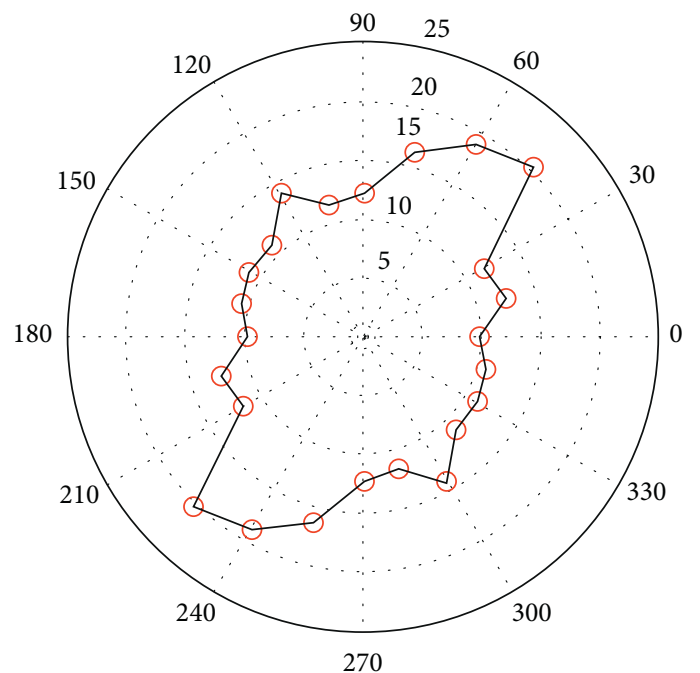

$\bigcirc R_{0}=r_{0}(m=1)$

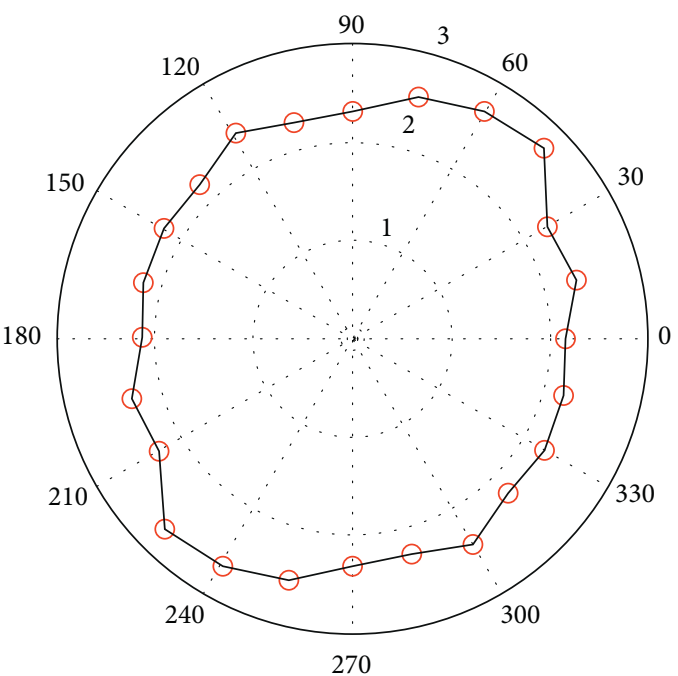

$\bigcirc R_{0}(m=3)$

(a)

(b)

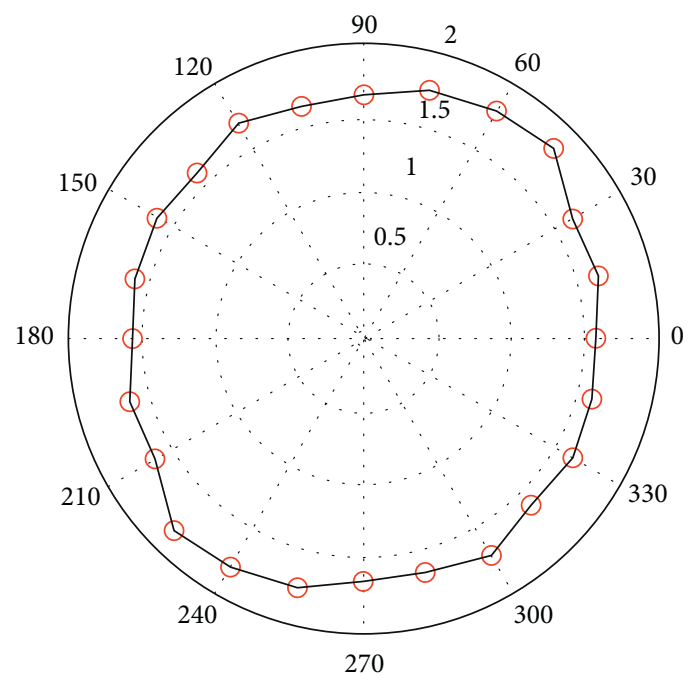

$R_{0}(m=5)$

(c)

Figure 1: Polar plots of the processed JRC values. (a) $m=1$; (b) $m=3$; (c) $m=5$.

$$
\begin{aligned}
& Z_{2}=\sqrt{\frac{1}{L} \int_{x=0}^{x=L}\left(\frac{d y}{d x}\right)^{2} d x} \approx \sqrt{\frac{1}{N} \sum_{i=1}^{N-1}\left[\frac{\left(y_{i+1}-y_{i}\right)}{\left(x_{i+1}-x_{i}\right)}\right]^{2}}, \\
& R_{p}=\frac{L_{t}}{L_{n}}=\frac{\sum_{i=1}^{N-1} \sqrt{\left(x_{i+1}-x_{i}\right)^{2}+\left(y_{i+1}-y_{i}\right)^{2}}}{L_{n}} \\
& L_{\theta *}=L_{0}\left(\frac{\theta_{\max }^{*}-\theta^{*}}{\theta_{\max }^{*}}\right)^{C} .
\end{aligned}
$$

To study the nature of the scale-dependency of rock joint roughness, Tatone [32] calculated the 2D roughness coefficients $Z_{2}, R_{p}$, and $\theta_{\text {max }}^{*} /(C+1)_{2 D}$ from a series of $2 \mathrm{D}$ profiles measured on a large-scale migmatitic-gneiss joint surface. These profiles are oriented between $0^{\circ}$ and $360^{\circ}$ at an angular increment of $30^{\circ}$, as shown in Figure 11. Figure 12 shows the results of the polar plots of these roughness parameters as obtained through Tatone's research.

The polar plots of these roughness parameters in Figure 12 present distinctly different shapes. Since the values of $Z_{2}$ and $R_{p}$ in opposing orientations are non-directional, the polar plots display inverted symmetry. The values of $\theta_{\max }^{*} /(C+1)_{2 D}$ in opposing orientations are generally different, and the $2 \mathrm{D}$ roughness in polar plots is random. The data series displayed in these polar plots appears erratic, with large variations in the roughness values for angularly 


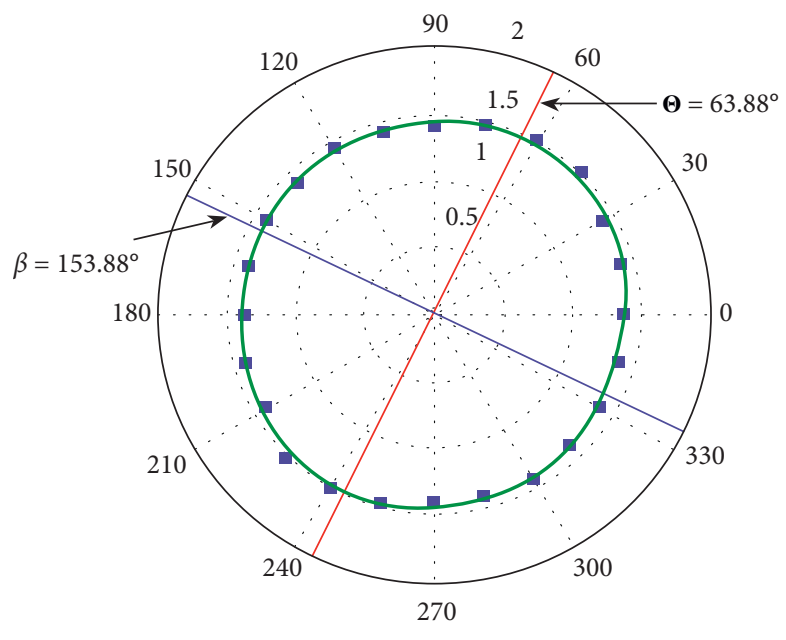

- $R_{0}\left(m_{0}=7.3\right)$

— Ellipse fitting curve

FIGURE 2: Polar plots of the processed JRC values by $m_{0}$ and its ellipse fitting curve.
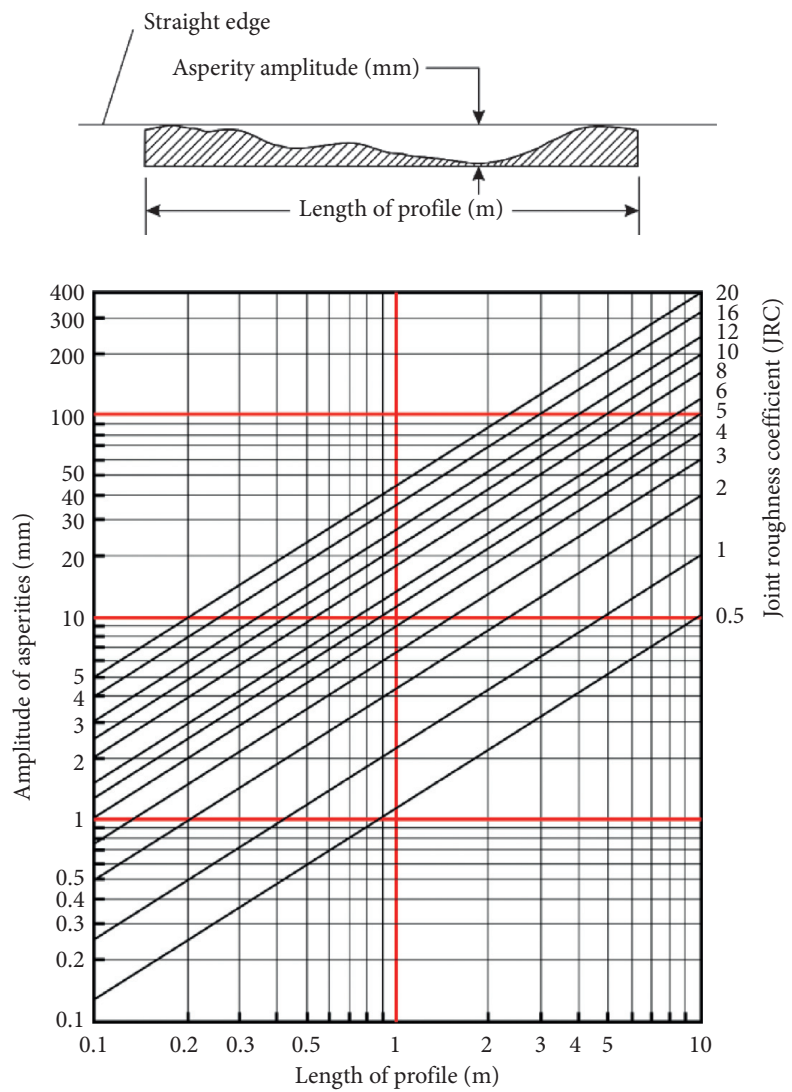

FIGURE 3: Alternative method for estimating JRC from measurements of surface roughness amplitude from a straight edge [35]. 
TABLE 2: Summary of JRC values of test samples obtained in different orientations and their variations with sample scale.

\begin{tabular}{|c|c|c|c|}
\hline Length of test profiles $(\mathrm{mm})$ & Numbers of test profiles & Orientation $\left({ }^{\circ}\right)$ & Average value of JRC \\
\hline \multirow{12}{*}{100} & 89 & $0 / 180 / 360$ & 13.8 \\
\hline & 39 & $15 / 195$ & 12.6 \\
\hline & 42 & $30 / 210$ & 10.8 \\
\hline & 38 & $45 / 225$ & 9.8 \\
\hline & 38 & $60 / 240$ & 9.1 \\
\hline & 38 & $75 / 255$ & 9.9 \\
\hline & 52 & $90 / 270$ & 7.7 \\
\hline & 39 & $105 / 285$ & 9.4 \\
\hline & 38 & $120 / 300$ & 10.1 \\
\hline & 40 & $135 / 315$ & 10.3 \\
\hline & 32 & $150 / 330$ & 10.4 \\
\hline & 33 & $165 / 345$ & 12.2 \\
\hline \multirow{12}{*}{200} & 48 & $0 / 180 / 360$ & 11.1 \\
\hline & 19 & $15 / 195$ & 10.1 \\
\hline & 17 & $30 / 210$ & 9.4 \\
\hline & 19 & $45 / 225$ & 7.8 \\
\hline & 20 & $60 / 240$ & 8.0 \\
\hline & 19 & $75 / 255$ & 6.1 \\
\hline & 44 & $90 / 270$ & 6.8 \\
\hline & 20 & $105 / 285$ & 8.3 \\
\hline & 10 & $120 / 300$ & 9.2 \\
\hline & 20 & $135 / 315$ & 8.5 \\
\hline & 22 & $150 / 330$ & 9.9 \\
\hline & 22 & $165 / 345$ & 10.5 \\
\hline \multirow{12}{*}{500} & 28 & $0 / 180 / 360$ & 9.0 \\
\hline & 10 & $15 / 195$ & 8.0 \\
\hline & 8 & $30 / 210$ & 7.5 \\
\hline & 10 & $45 / 225$ & 6.4 \\
\hline & 10 & $60 / 240$ & 6.4 \\
\hline & 9 & $75 / 255$ & 5.1 \\
\hline & 28 & $90 / 270$ & 5.3 \\
\hline & 10 & $105 / 285$ & 6.0 \\
\hline & 10 & $120 / 300$ & 5.7 \\
\hline & 8 & $135 / 315$ & 5.8 \\
\hline & 9 & $150 / 330$ & 7.8 \\
\hline & 10 & $165 / 345$ & 8.8 \\
\hline \multirow{12}{*}{1000} & 14 & $0 / 180 / 360$ & 6.0 \\
\hline & 5 & $15 / 195$ & 6.1 \\
\hline & 5 & $30 / 210$ & 5.8 \\
\hline & 5 & $45 / 225$ & 4.7 \\
\hline & 5 & $60 / 240$ & 3.4 \\
\hline & 3 & $75 / 255$ & 3.7 \\
\hline & 14 & $90 / 270$ & 3.6 \\
\hline & 5 & $105 / 285$ & 4.4 \\
\hline & 5 & $120 / 300$ & 3.6 \\
\hline & 5 & $135 / 315$ & 5.0 \\
\hline & 4 & $150 / 330$ & 4.9 \\
\hline & 5 & $165 / 345$ & 5.8 \\
\hline
\end{tabular}




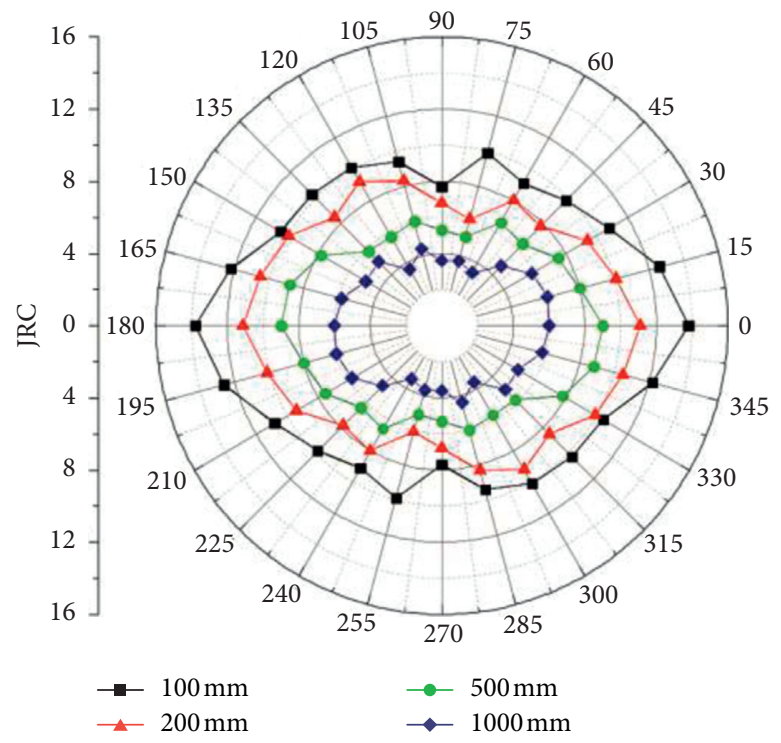

FIGURE 4: Polar plots of JRC values of different sized roughness surfaces.

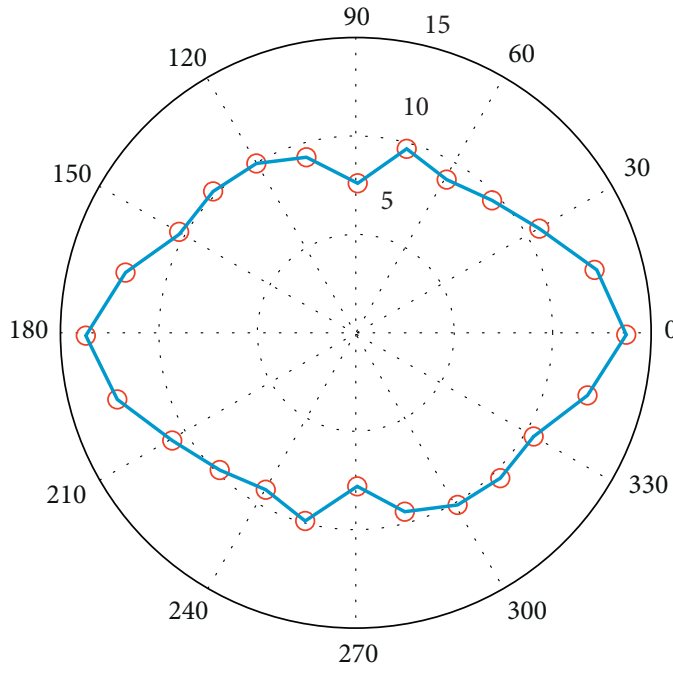

○ $r_{0}(m=1)$

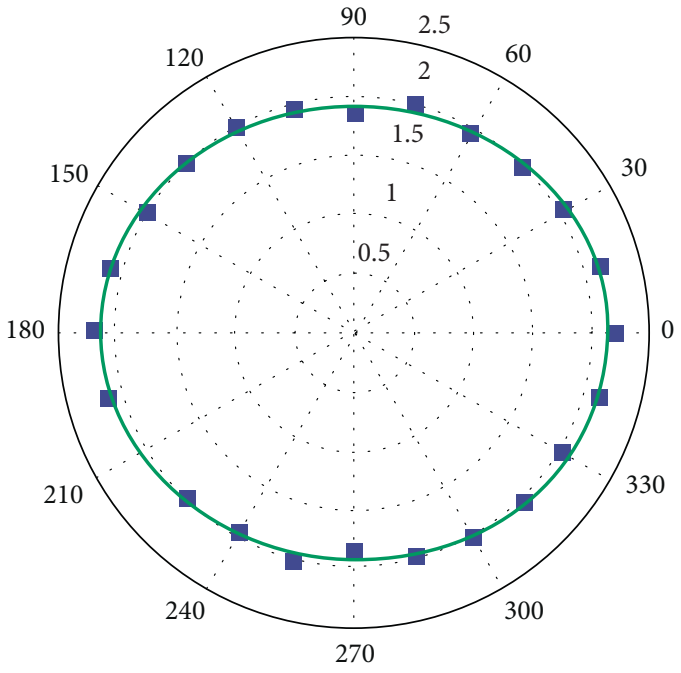

- $R_{0}\left(m_{0}=3.3\right)$

Ellipse fitting curve

(a)

(b)

FIGURE 5: Polar plots of the original and processed JRC values and the ellipse fitting curves of the test samples in the length of $100 \mathrm{~mm}$.

adjacent profiles. Curves of $\theta_{\max }^{*} /(C+1)_{2 D}$ are closer to ellipse shape, while the curves of $R_{p}$ are highly irregular and quite hard to be approximated by ellipse functions directly.

The roughness smooth coefficient values of $m_{0}$ for $Z_{2}, R_{p}$, and $\theta_{\max }^{*} /(C+1)_{2 D}$ for the polar plots are shown in Figure 13. Due to the different definitions of the roughness parameters, the corresponding smooth coefficients for $Z_{2}$, $R_{p}$, and $\theta_{\max }^{*} /(C+1)_{2 D}$ are not identical by the smooth process using class ratio transform. Generally, the roughness smooth coefficient for $\theta_{\max }^{*} /(C+1)_{2 D}$ is comparatively smaller than that of $Z_{2}$ or $R_{p}$ on the same series of $2 \mathrm{D}$ profiles. The roughness smooth coefficient for $Z_{2}$ is approximately between the values of $R_{p}$ and $\theta_{\max }^{*} /(C+1)_{2 D}$ under the same size; the roughness smooth coefficient for $R_{p}$ reaches the greatest value. The highest roughness smooth coefficient for $R_{p}$ indicates the polar plot curve of $R_{p}$ is more irregular than that of $Z_{2}, \theta_{\max }^{*} /(C+1)_{2 D}$. The roughness smooth coefficient for $\theta_{\max }^{*} /(C+1)_{2 D}$ has the lowest value which means its polar plot curve is closer to an elliptical shape. The estimations on roughness anisotropy by class 


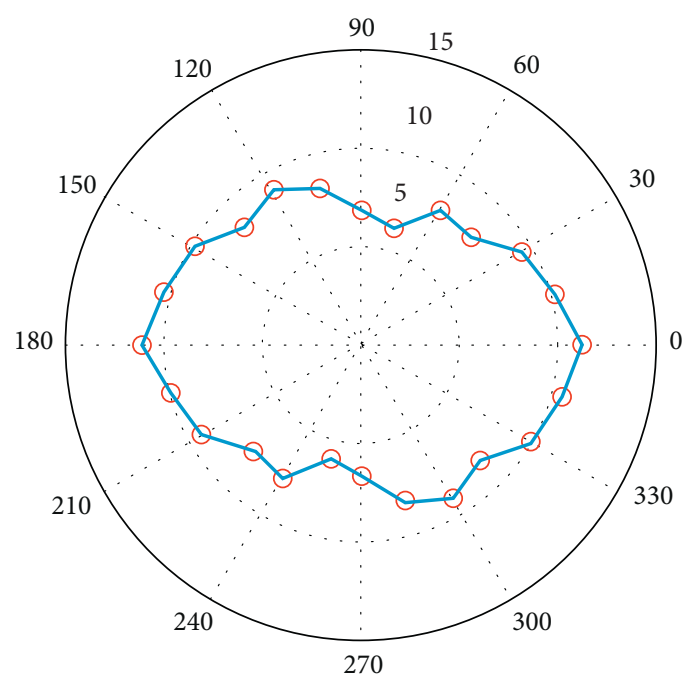

$r_{0}(m=1)$

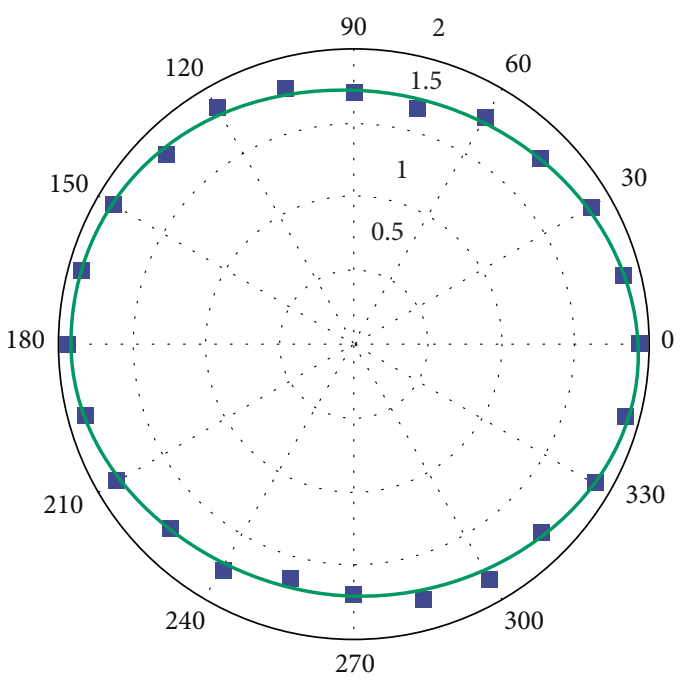

- $R_{0}\left(m_{0}=3.6\right)$

- Ellipse fitting curve

(a)

(b)

FIgURE 6: Polar plots of the original and processed JRC values and the ellipse fitting curves of the test samples in the length of $200 \mathrm{~mm}$.

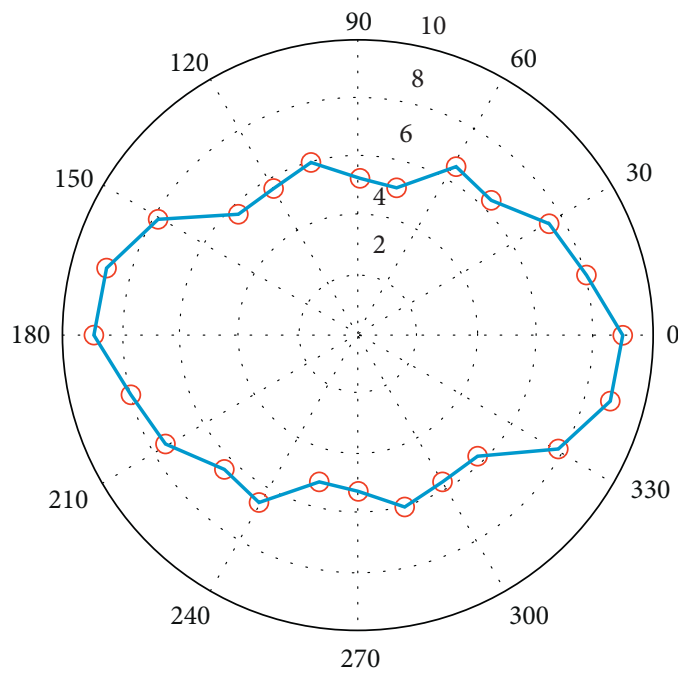

$r_{0}(m=1)$

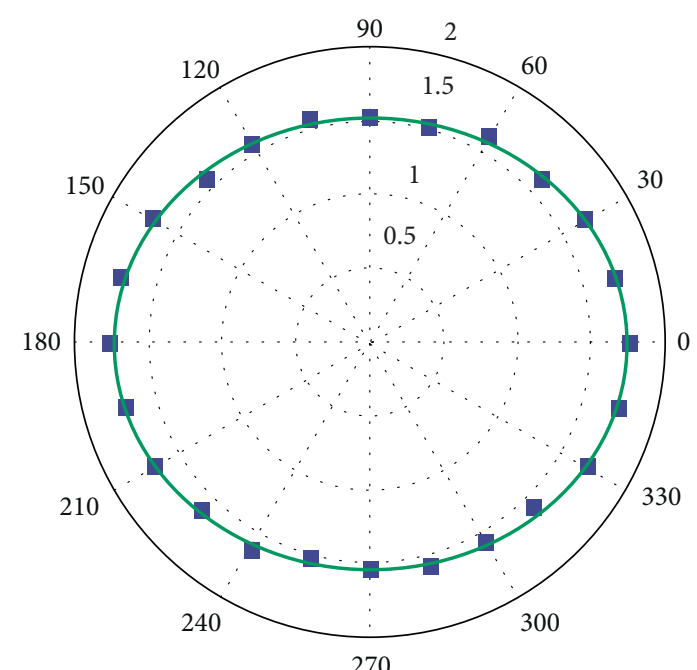

- $R_{0}\left(m_{0}=3.9\right)$

- Ellipse fitting curve

(b)

FIGURE 7: Polar plots of the original and processed JRC values and the ellipse fitting curves of the test samples in the length of $500 \mathrm{~mm}$. 


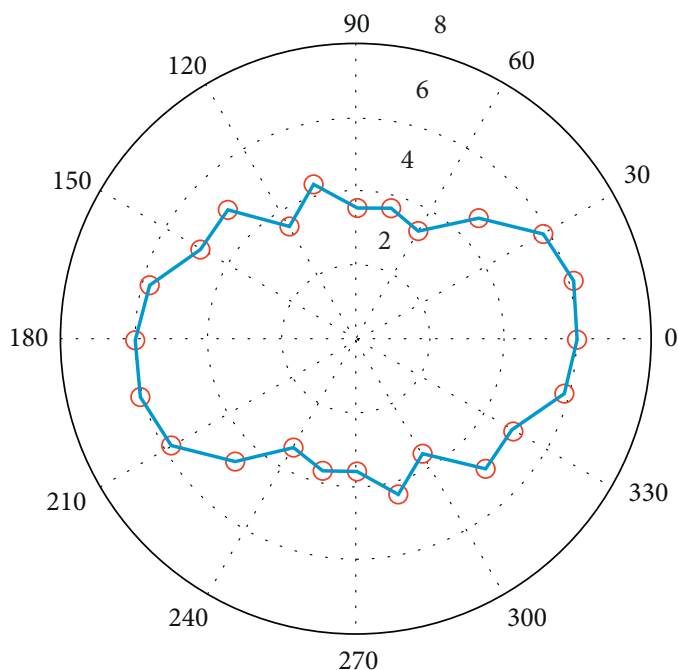

$r_{0}(m=1)$

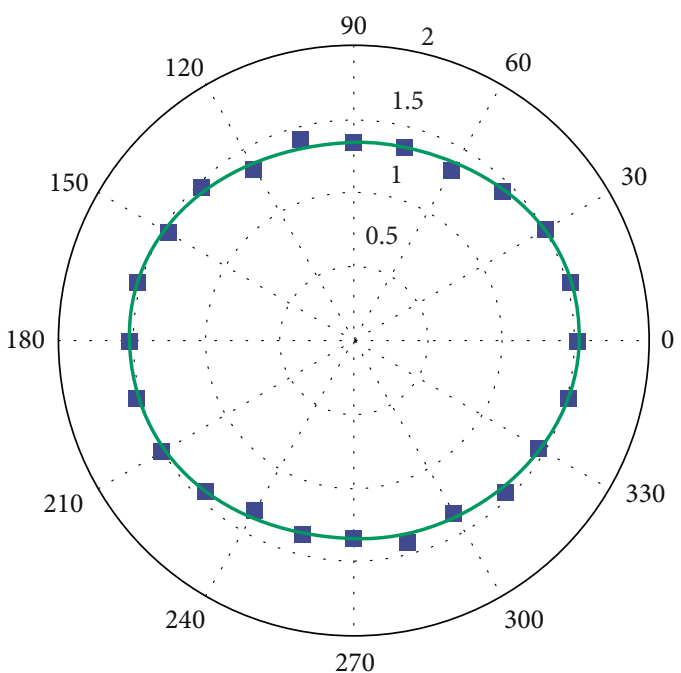

- $R_{0}\left(m_{0}=4.3\right)$

— Ellipse fitting curve

(a)

(b)

FIgUre 8: Polar plots of the original and processed JRC values and the ellipse fitting curves of the test samples in the length of $1000 \mathrm{~mm}$.

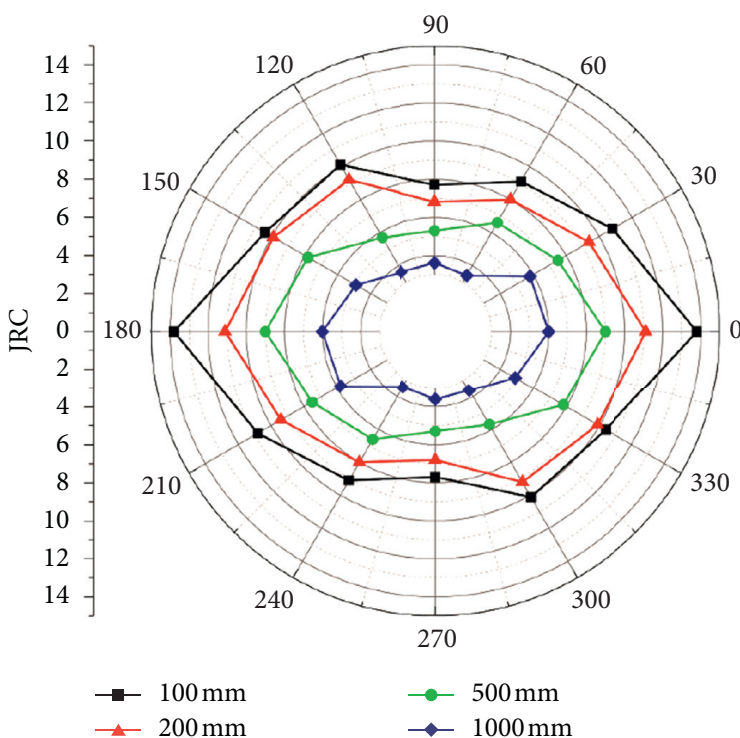

(a)

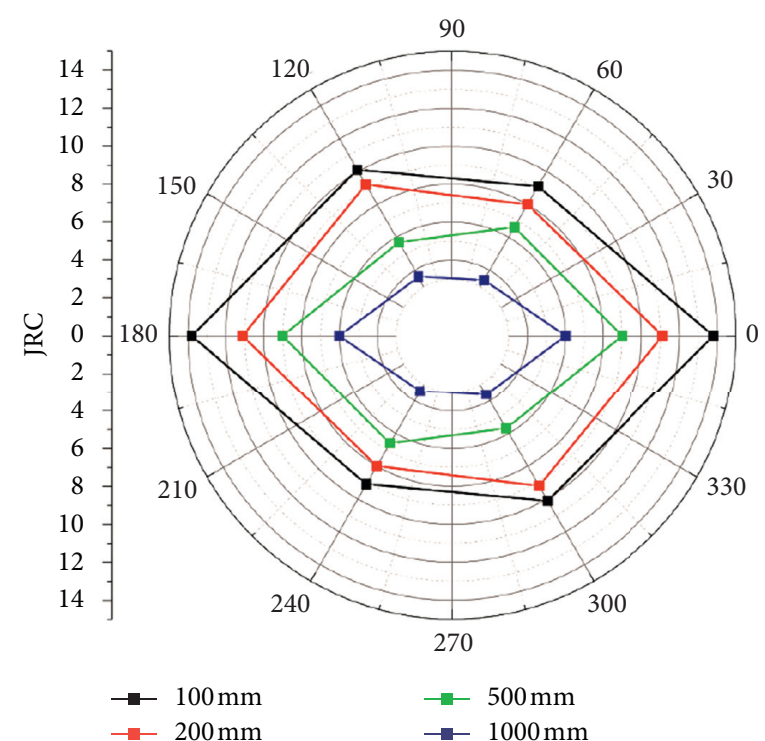

(b)

Figure 9: Polar plots of JRC values in the azimuthal intervals of $30^{\circ}$ and $60^{\circ}$.

ratio transform method are consistent with direct observation on polar plots. Therefore, the irregularities of curve shapes of $Z_{2}, R_{p}$, and $\theta_{\max }^{*} /(C+1)_{2 D}$ in polar plots can be quantified by the roughness smooth coefficient values $m_{0}$.

Although the definitions of $Z_{2}, R_{p}$, and $\theta_{\max }^{*} /(C+1)_{2 D}$ are different, there exist high correlations among these roughness coefficients [41]. The roughness smooth coefficients for $Z_{2}, R_{p}$, and $\theta_{\text {max }}^{*} /(C+1)_{2}$ are dissimilar. Their values indicate similar variation trend with the sample size changing from $100 \mathrm{~mm}$ to $1800 \mathrm{~mm}$. Their similar variation trends with sample sizes demonstrate a definite consistency on illustrating the roughness anisotropy of the rock joints.

The polar plots of the 2D roughness values (Figure 12) show the positive scale effect which may be attributed to the relationships of sample size and the roughness values. It should be noted that the positive scale effect is less apparent in some orientations. In Figure 13, the roughness smooth coefficient changes with the sample length and it presents fluctuated improving trends in the roughness smooth coefficients of $Z_{2}, R_{p}$, and $\theta_{\max }^{*} /(C+1)_{2 D}$. The anisotropy of 


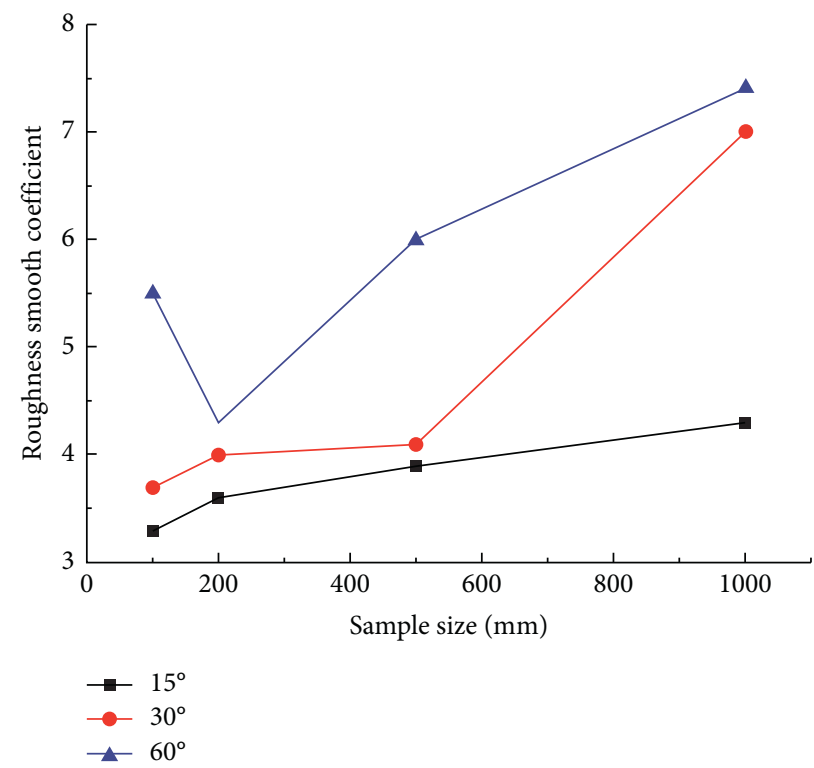

Figure 10: Roughness smooth coefficient of JRC values in different azimuthal intervals.

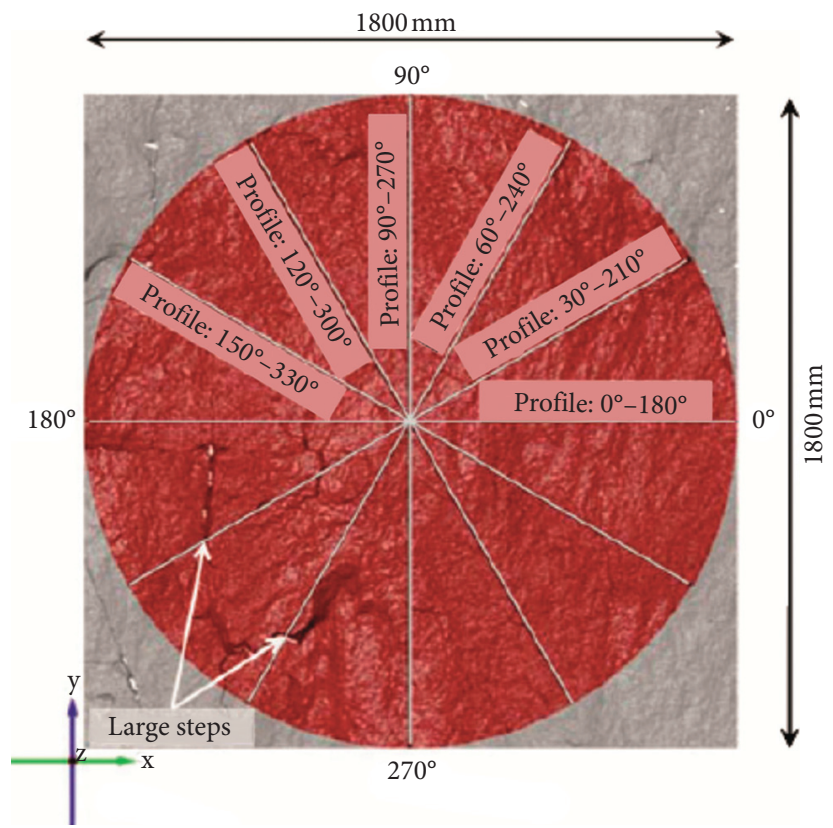

FIgURE 11: The location and orientation of the 2D profiles extracted from the square sampling window [29].

surface roughness reaches the most irregular condition when the sample size increased to $1500 \mathrm{~mm}$.

Therefore, the roughness anisotropy and its variation with scale can be evaluated by the roughness smooth coefficients of different roughness parameters proposed through previous projects/research. The roughness smooth coefficients can reflect the roughness anisotropy from any aspects of roughness definition as identified by the researcher. 

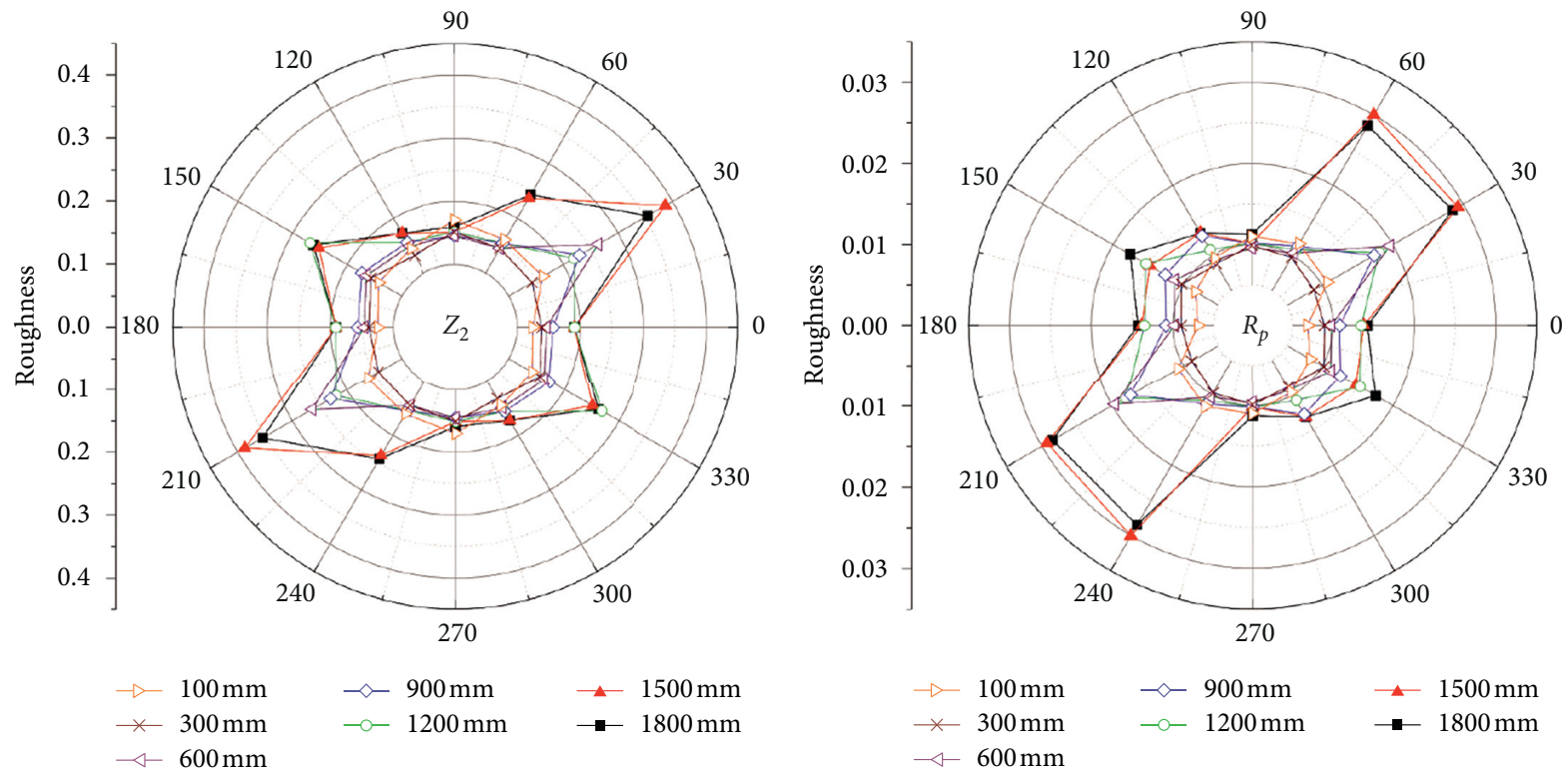

(a)

(b)

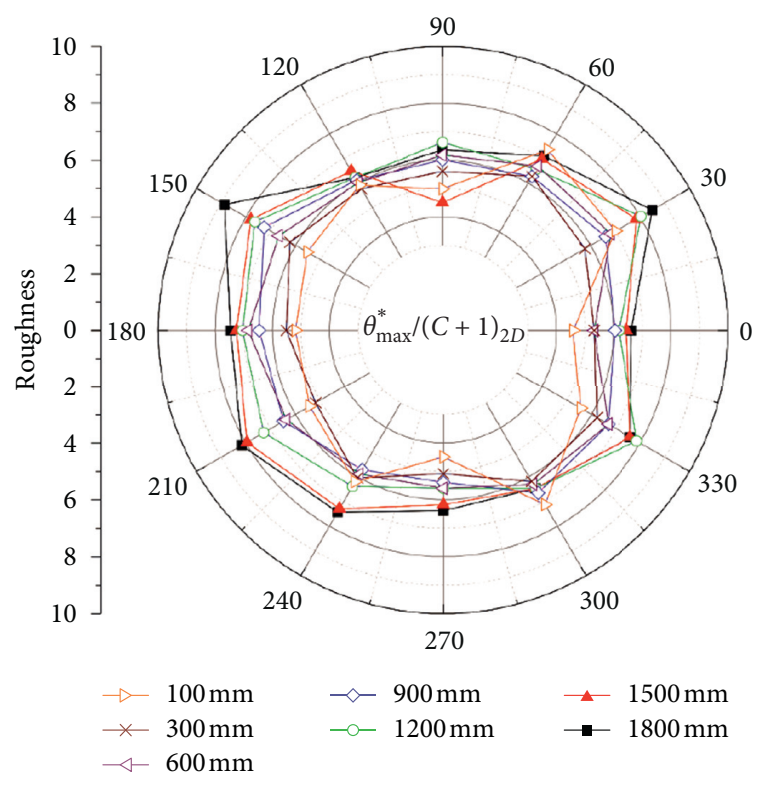

(c)

FIgURE 12: Polar plots of roughness parameters $Z_{2}, R_{p}$, and $\theta_{\max }^{*} /(C+1)_{2 D}$ on the rock joint surface [29]. 


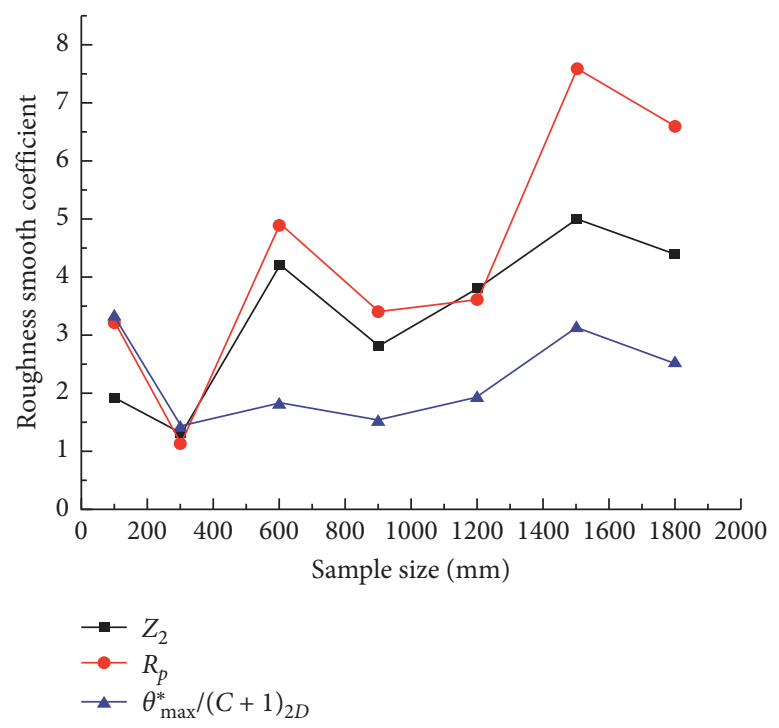

Figure 13: Roughness smooth coefficients of $m_{0}$ for $Z_{2}, R_{p}$, and $\theta_{\max }^{*} /(C+1)_{2 D}$ on the rock joint surface.

\section{Conclusions}

A new method is proposed for quantifying the roughness anisotropy of natural rock joint surfaces. To approximate the polar plots of roughness parameters with ellipse function, a class ratio transform method is utilized for smoothing the variations of roughness parameters. In this way, the directional variability of processed roughness data tends to exhibit a relatively systematic variation that can be described by the ellipse function with high fitting precision. The characteristic coefficients of ellipse function allow for the detection of higher orders of anisotropy, which would be represented by the major principal axis of ellipse curves. The class ratio transform coefficient $m_{0}$ is defined as the roughness smooth coefficient and it is a parameter for quantitatively describing the apparent anisotropy of roughness surface. This method was utilized for the evaluation of joint roughness anisotropy by JRC in the case study. The result shows that the roughness anisotropy of large-sized rock joints is more evident than that of small ones. The comparison between different azimuthal intervals shows that the roughness smooth coefficients get smaller values when the azimuthal interval decreases, and the differences caused by azimuthal interval variation are magnified in large-sized rock joints. This method demonstrated its effectiveness by analyzing surface anisotropy using different roughness parameters. The values of roughness smooth coefficients are not identical using different roughness parameters, but they exhibit similar variation trends with the sample size increasing.

\section{Data Availability}

The data used to support the findings of this study are available from the corresponding author upon request.

\section{Conflicts of Interest}

The authors declare that there are no conflicts of interest regarding the publication of this paper.

\section{Acknowledgments}

This study was funded by the National Natural Science Foundation of China (No. 41502300), Zhejiang Provincial Natural Science Foundation (No. LQ16D020001), and Zhejiang Collaborative Innovation Center for Prevention and Control of Mountain Geological Hazards (No. PCMGH-2017-Z03).

\section{References}

[1] S. Du, S. Xu, and S. Yang, "Application of rock quality designation (RQD) to engineering classification of rocks," Journal of Engineering Geology, vol. 8, no. 3, pp. 351-356, 2000.

[2] R. Yong, X. Fu, M. Huang, Q. Liang, and S.-G. Du, "A rapid field measurement method for the determination of joint roughness coefficient of large rock joint surfaces," KSCE Journal of Civil Engineering, vol. 22, no. 1, pp. 101-109, 2017.

[3] R. Yong, J. Qin, M. Huang, S. Du, J. Liu, and G. Hu, "An innovative sampling method for determining the scale effect of rock joints," Rock Mechanics and Rock Engineering, vol. 52, no. 3, pp. 935-946, 2019.

[4] L. Huang, X. Su, and H. Tang, "Optimal selection of estimator for obtaining an accurate three-dimensional rock fracture orientation distribution," Engineering Geology, vol. 270, Article ID 105575, 2020.

[5] R. Yong, J. Ye, B. Li, and S. G. Du, "Determining the maximum sampling interval in rock joint roughness measurements using Fourier series," International Journal of Rock Mechanics and Mining Sciences, vol. 101, pp. 78-88, 2018.

[6] L. Huang, H. Tang, L. Wang, and C. H. Juang, "Minimum scanline-to-fracture angle and sample size required to produce a highly accurate estimate of the 3-D fracture orientation distribution," Rock Mechanics and Rock Engineering, vol. 52, no. 3, pp. 803-825, 2019.

[7] T. Koyama, N. Fardin, L. Jing, and O. Stephansson, "Numerical simulation of shear-induced flow anisotropy and scale-dependent aperture and transmissivity evolution of rock fracture replicas," International Journal of Rock Mechanics and Mining Sciences, vol. 43, no. 1, pp. 89-106, 2006. 
[8] T. Belem, M. Souley, and F. Homand, "Modeling surface roughness degradation of rock joint wall during monotonic and cyclic shearing," Acta Geotechnica, vol. 2, no. 4, pp. 227-248, 2007.

[9] A. Giacomini, O. Buzzi, A. M. Ferrero, M. Migliazza, and G. P. Giani, "Numerical study of flow anisotropy within a single natural rock joint," International Journal of Rock Mechanics and Mining Sciences, vol. 45, no. 1, pp. 47-58, 2008.

[10] N. Barton and E. Quadros, "Anisotropy is everywhere, to see, to measure, and to model," Rock Mechanics and Rock Engineering, vol. 48, no. 4, pp. 1323-1339, 2015.

[11] J. Mah, C. Samson, SD. McKinnon, and D. Thibodeau, "3D laser imaging for surface roughness analysis," International Journal of Rock Mechanics and Mining Sciences, vol. 58, pp. 111-117, 2013.

[12] T. Belem, F. Homand-Etienne, and M. Souley, "Quantitative parameters for rock joint surface roughness," Rock Mechanics and Rock Engineering, vol. 33, no. 4, pp. 217-242, 2000.

[13] D. S. Bae, K. S. Kim, Y. K. Koh et al., "Characterization of joint roughness in granite by applying the scan circle technique to images from a borehole televiewer," Rock Mechanics \& Rock Engineering, vol. 44, no. 4, pp. 497-504, 2011.

[14] Z. Yang, C. Di, and S. Lo, "Two-dimensional Hurst index of joint surfaces," Rock Mechanics and Rock Engineering, vol. 34, no. 4, pp. 323-345, 2001.

[15] P. H. Kulatilake, P. Balasingam, J. Park, and R. Morgan, "Natural rock joint roughness quantification through fractal techniques," Geotechnical \& Geological Engineering, vol. 24, no. 5, pp. 1181-1202, 2006.

[16] B. R. Baker, K. Gessner, E. J. Holden, and A. P. Squelch, "Automatic detection of anisotropic features on rock surfaces," Geosphere, vol. 4, no. 2, pp. 418-428, 2008.

[17] N. Fardin, "Influence of structural non-stationarity of surface roughness on morphological characterization and mechanical deformation of rock joints," Rock Mechanics and Rock Engineering, vol. 41, no. 2, pp. 267-297, 2008.

[18] B. S. Tatone and G. Grasselli, "An investigation of discontinuity roughness scale dependency using high-resolution surface measurements," Rock Mechanics and Rock Engineering, vol. 46, no. 4, pp. 657-681, 2013.

[19] R. Yong, L. Gu, J. Ye et al., "Neutrosophic function with NNs for analyzing and expressing anisotropy characteristic and scale effect of joint surface roughness," Mathematical Problems in Engineering, vol. 2019, pp. 1-11, 2019.

[20] N. Fardin, O. Stephansson, and L. Jing, "The scale dependence of rock joint surface roughness," International Journal of Rock Mechanics and Mining Sciences, vol. 38, no. 5, pp. 659-669, 2001.

[21] G. Grasselli, J. Wirth, and P. Egger, "Quantitative three-dimensional description of a rough surface and parameter evolution with shearing," International Journal of Rock Mechanics and Mining Sciences, vol. 39, no. 6, pp. 789-800, 2002.

[22] B. S. Tatone and G. Grasselli, "A new 2D discontinuity roughness parameter and its correlation with JRC," International Journal of Rock Mechanics and Mining Sciences, vol. 47, no. 8, pp. 1391-1400, 2010.

[23] Y. Ge, H. Tang, M. M. E. Eldin, P. Chen, L. Wang, and J. Wang, "A description for rock joint roughness based on terrestrial laser scanner and image analysis," Scientific Reports, vol. 5, pp. 1-10, 2015.

[24] P. H. Kulatilake, J. Park, P. Balasingam, and R. Morgan, "Quantification of aperture and relations between aperture, normal stress and fluid flow for natural single rock fractures," Geotechnical and Geological Engineering, vol. 26, no. 3, pp. 269-281, 2008.
[25] N. Babanouri, S. K. Nasab, and S. Sarafrazi, "A hybrid particle swarm optimization and multi-layer perceptron algorithm for bivariate fractal analysis of rock fractures roughness," International Journal of Rock Mechanics and Mining Sciences, vol. 60 , pp. 66-74, 2013.

[26] L. Jing, E. Nordlund, and O. Stephansson, “An experimental study on the anisotropy and stress-dependency of the strength and deformability of rock joints," In International Journal of Rock Mechanics and Mining Sciences \& Geomechanics Abstracts, vol. 29, no. 6, pp. 535-542, 1992.

[27] S. Ying and W. Yong, "The Grey model based on class ratio modeling," in Proceedings of the Chinese Control and Decision Conference, pp. 2404-2408, June 2009, https://doi.org/10. 1109/CCDC.2009.5192495.

[28] B. Yang, Z. Fang, and K. Zhang, "Discrete GM $(1,1)$ model based on sequence of stepwise ratio," Systems Engineering and Electronics, vol. 34, no. 4, pp. 715-718, 2012.

[29] J. L. Deng, "On judging the admissibility of grey modelling via class ratio," The Journal of Grey System, vol. 21, no. 4, pp. 249-252, 1993.

[30] K. Wen, J. Dai, T. C. Chang, and C. C. Tong, "The discussions of class ratio for AGO algorithm in grey theory," in Proceedings of 2001 IEEE Conference on Systems Man and Cybernetics Conference, pp. 7-11, Tucson, AZ, USA, October 2001.

[31] X. Q. Kang, W. Yong, and S. Ying, "The class ratio modeling method of non-equigap GM $(1,1)$ model," in Proceedings of the the 2009 International Symposium On Information Processing (ISIP 2009), p. 286, San Francisco, CA, USA, April 2009.

[32] B. S. A. Tatone, "Quantitative characterization of natural rock discontinuity roughness in-situ and in the laboratory," Master's thesis, University of Toronto, Toronto, Canada, 2009.

[33] S. Du, Y. Hu, and X. Hu, "Measurement of joint roughness coefficient by using profilograph and roughness ruler," Journal of Earth Science, vol. 20, no. 5, pp. 890-896, 2009.

[34] G. L. Morelli, "On joint roughness: measurements and use in rock mass characterization," Geotechnical and Geological Engineering, vol. 32, no. 2, pp. 345-362, 2014.

[35] N. Barton, "Shear strength investigations for surface mining," in Proceedings of the 3rd International Conference on Stability Surface Mining, pp. 171-196, Vancouver, Canada, June 1981.

[36] N. Barton, "Review of a new shear-strength criterion for rock joints," Engineering Geology, vol. 7, no. 4, pp. 287-332, 1973.

[37] R. Tse and D. M. Cruden, "Estimating joint roughness coefficients," International Journal of Rock Mechanics and Mining Sciences, vol. 16, no. 5, pp. 303-307, 1979.

[38] N. H. Maerz, J. A. Franklin, and C. P. Bennett, "Joint roughness measurement using shadow profilometry," International Journal of Rock Mechanics and Mining Sciences, vol. 27, no. 5, pp. 329-343, 1990.

[39] G. Grasselli and P. Egger, "Constitutive law for the shear strength of rock joints based on three-dimensional surface parameters," International Journal of Rock Mechanics and Mining Sciences, vol. 40, no. 1, pp. 25-40, 2003.

[40] E. S. Hong, J. S. Lee, and I. M. Lee, "Underestimation of roughness in rough rock joints," International Journal for Numerical and Analytical Methods in Geomechanics, vol. 32, no. 11, pp. 1385-1403, 2008.

[41] P. Alameda-Hernández, J. Jiménez-Perálvarez, J. A. Palenzuela et al., "Improvement of the JRC calculation using different parameters obtained through a new survey method applied to rock discontinuities," Rock Mechanics and Rock Engineering, vol. 47, no. 6, pp. 2047-2060, 2014. 